\title{
When should unexpected weight loss warrant further investigation to exclude cancer?
}

\author{
Brian D Nicholson clinical researcher ${ }^{1}$, Paul Aveyard professor of behavioural medicine ${ }^{1}$, Willie \\ Hamilton professor of primary care diagnostics ${ }^{2}$, F D Richard Hobbs Nuffield professor of primary \\ care $^{1}$
}

${ }^{1}$ Nuffield Department of Primary Care Health Sciences, University of Oxford OX2 6GG, UK; ${ }^{2}$ Medical School, University of Exeter, UK

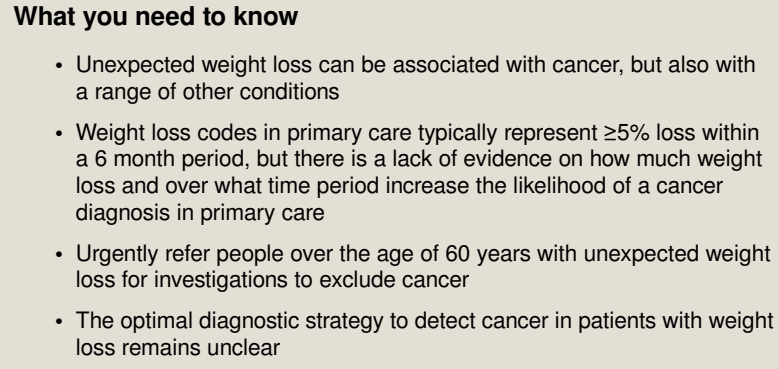

- Unexpected weight loss can be associated with cancer, but also with a range of other conditions

- Weight loss codes in primary care typically represent $\geq 5 \%$ loss within a 6 month period, but there is a lack of evidence on how much weight loss and over what time period increase the likelihood of a cancer diagnosis in primary care

- Urgently refer people over the age of 60 years with unexpected weight loss for investigations to exclude cancer

- The optimal diagnostic strategy to detect cancer in patients with weight loss remains unclear

Unexpected weight loss presents a diagnostic challenge in primary care. It is associated with a wide range of benign and serious conditions (box 1 ). ${ }^{1}$

\footnotetext{
Box 1: Differential diagnosis for patients with unexpected weight loss $^{1}$

Cardiovascular-End stage heart failure (cardiac cachexia)

Endocrine-Adrenal insufficiency, diabetes, hyperthyroidism

Gastrointestinal-Diarrhoea, colitis, malabsorption, mesenteric ischaemia

Infection-Chronic infection (such as HIV, tuberculosis)

Malignancy —Solid tumours more likely than haematological malignancies

Medication-Antidepressants, antiepileptics, anxiolytics, diuretics,

laxatives, stimulants

Neurological-Dementia, multiple sclerosis, neuromuscular disease,

Parkinson's disease, stroke

Psychiatric-Anorexia nervosa, anxiety, bulimia, depression

Renal-End stage renal failure (uraemic cachexia)

Respiratory-Chronic obstructive pulmonary disease (COPD), interstitial lung disease, vasculitis

Rheumatologic-Rheumatoid arthritis

Social-Excess alcohol consumption, neglect, use of opiates, poor oral health, poverty, smoking
}

Weight loss may be missed or misattributed because of several factors (see box 2). Once it is detected, the uncertainty for clinicians is not about whether unexpected weight loss is a symptom of concern, it is about who should be investigated further and who can be spared unnecessary investigation. Specifically, how much weight loss, over how much time, in combination with what other clinical features makes cancer sufficiently likely to warrant urgent investigation?

\section{Box 2: Challenges in detecting weight loss in primary care} Physiological factors

- Being overweight both increases the risk of cancer and the challenge of detecting weight loss ${ }^{2}$

- Gradual decline in muscle mass is expected from the sixth decade of life $^{3}$

- Diurnal fluctuations in body weight of $\pm 2 \mathrm{~kg}$ occur from changes in fluid balance and gut contents ${ }^{4}$

Measurement factors

- Weight measurement is not routine practice in many health systems; it is most commonly measured in people with particular clinical problems

- Clinicians record weight status in kg, pounds, or body mass index (BMI), making detection of weight loss slower ${ }^{6}$

- Patients delay attending their clinician with weight loss for longer than other symptoms of cancer

- Intentional weight loss and exercise complicate the interpretation of weight change ${ }^{5}$

\section{Sources and selection criteria}

We searched Embase, Medline, Web of Science, and the Cochrane Library for systematic reviews and primary studies using the following terms and related terms: neoplasia, weight loss, symptoms, diagnosis, general practice, family practice, primary care. 


\section{What is the evidence of uncertainty? How much weight loss over how long?}

The degree of weight loss that best indicates underlying cancer in primary care remains poorly defined. ${ }^{5}$ Almost all studies in this area are retrospective observational studies that define weight loss by means of a code entered into the electronic health record (table 1). ${ }^{5}$ These codes are based on general practitioners' decisions that the degree of weight loss is sufficiently concerning to justify recording it. Studies have not reported associated weight measurement data, quantified how much weight loss has occurred, or established whether patient-reported weight loss is more accurate at identifying disease than clinician-measured weight loss.

The percentage loss of weight is likely to be most clinically relevant, as change relative to baseline weight is more meaningful than the absolute change. ${ }^{4}$ A study of more than 50 000 weight loss codes entered into English electronic health records showed that a code for unexpected weight loss represents a mean weight loss of $\geq 5 \%$ within a six month period in primary care. ${ }^{33}$ Across methods of estimation, weight loss ranged from $-5.4 \%$ to $-8.3 \%$ in females and $-4.8 \%$ to $-7.4 \%$ in males, with greater weight loss being observed in elderly people. This resembles the 5-10\% weight loss within 6-12-months that is most commonly cited as significant based on data from high risk populations, such as those referred or admitted to secondary care. ${ }^{1434-36}$ One case-control study from a primary care database used weight measurements to define weight loss in relation to the risk of colorectal cancer diagnosis. ${ }^{6}$ The odds ratio for a $5-9.9 \%$ weight loss was 1.2 (95\% confidence interval 0.99 to 1.5 ), and for $\geq 10 \%$ loss it was 2.5 (2.1 to 3.0). Weight loss was defined by using the highest recorded weight in the preceding two years, meaning it could have been underestimated or overestimated.

We are much less clear how recently weight loss must have occurred to indicate the presence of cancer. Studies have investigated the diagnostic utility of weight loss occurring at any point in the past two years. It seems more plausible that weight loss in the recent past signifies the presence of cancer, though there is no evidence of this. ${ }^{5}$

\section{Which cancers are associated with weight loss in primary care?}

A recent systematic review and meta-analysis (25 studies) examined the likelihood of a cancer diagnosis in adults presenting to primary care with weight loss. ${ }^{5}$ More than one in 10 people aged over 60 years reporting weight loss were subsequently diagnosed with cancer; a risk of $3-7 \%$ in women and $11-14 \%$ in men. ${ }^{5}$ The National Institute for Health and Care Excellence (NICE) recommends urgent investigation when the risk of cancer exceeds 3\% threshold for urgent investigation suggested by ${ }^{37}$ Weight loss predicted the presence of prostate, colorectal, lung, gastro-oesophageal, pancreatic, non-Hodgkin's lymphoma, ovarian, myeloma, renal tract, and biliary tree cancers. ${ }^{5}$ Table 1 describes the findings of studies included in the systematic review. Subsequently two case-control studies using UK and Swedish medical registries suggest that weight loss was associated with a diagnosis of acute and chronic leukaemia and of non-metastatic colorectal cancer. ${ }^{38} 39$

\section{Weight loss in isolation or with other clinical features?}

No study in primary care has reported whether weight loss without any other symptoms predicts cancer. However, studies show that weight loss predicts cancer even after adjusting for the presence of other symptoms. ${ }^{6} 10131416-2325-2729-313940$ For example, in cohort studies, patients with weight loss are 1.6 times to 12.5 times more likely to have cancer than a patient without weight loss (table 1). ${ }^{114252731}$ Weight loss is the second most powerful predictor of cancer after: rectal bleeding in colorectal cancer; haemoptysis in lung cancer, rib pain in myeloma; jaundice in pancreatic cancer; and haematuria in renal tract cancer. ${ }^{41}$ It is the third most powerful predictor in non-Hodgkin's lymphoma and gastro-oesophageal cancers. ${ }^{41}$ Table 2 shows the additive risk of cancer in patients with weight loss in addition to another localising clinical feature as calculated in case-control studies using primary care records data. 6101617192229303940

\section{Is weight loss associated only with late stage cancer?}

Weight loss can occur at any stage of cancer precipitated by biochemical, behavioural, functional, and metabolic factors (box 3). ${ }^{1}$ Only a few studies have examined weight loss in relation to cancer stage in primary care. A US case-control study found no relationship between weight loss and stage in pancreatic cancer. ${ }^{43}$ A UK case-control study found no association between weight loss and stage IV prostate, colorectal, lung, and breast cancer. ${ }^{40}$ Similar positive predictive values for weight loss were reported for colorectal cancer in Swedish and UK case-control studies. The former included cancer stages I-III (PPV 1.0\% (95\% CI 0.3 to 3.0$)$ ) and the latter included stages I-IV (1.2\% (0.91 to 1.6$))^{3844}$

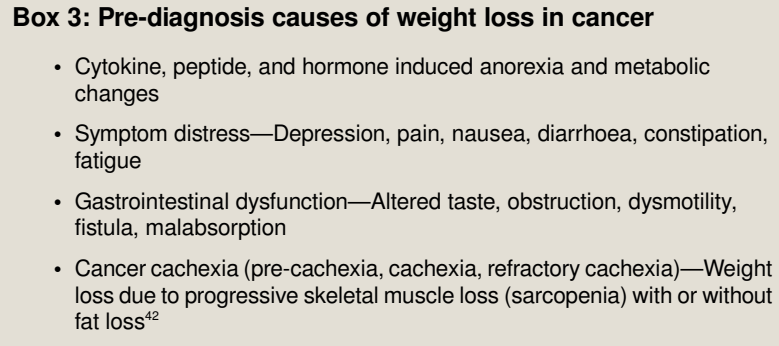

\section{Is ongoing research likely to provide relevant evidence?}

We searched clinicaltrials.gov, PROSPERO, Cochrane Library, National Cancer Research Institute portfolio, Cancer Research UK, and Macmillan websites and found no ongoing trials examining strategies to investigate patients presenting with unexpected weight loss in primary care. A systematic review aims to identify the value of tools used to assess cachexia, not specifically in cancer. ${ }^{45}$

The UK National Institute of Health Research (NIHR) has funded research into weight loss as a predictor of cancer in primary care using primary care electronic health records data from the UK and US and to establish whether routine weighing is feasible in English primary care. ${ }^{5}$ In many healthcare systems, this does not occur, and we need to know how acceptable and useful this would be.

Recent imaging studies have shown evidence of skeletal muscle loss (sarcopenia) suggesting cachexia in patients with non-metastatic cancer with and without weight loss. ${ }^{4647}$ Protein markers of tissue wasting are present in the blood before clinically detectable pancreatic cancer. ${ }^{43} 4849$ These biochemical and radiological signatures of cachexia offer promise in 
detecting weight loss related to cancer, but none has been formally investigated in primary care. ${ }^{5051}$

The UK has introduced multidisciplinary diagnostic centres to assess people with symptoms such as weight loss but no localising symptoms. Each operates differently. Some, modelled on the Danish approach, ask GPs to conduct tests before referral, others offer a clinic appointment before investigation, and some offer imaging as an initial investigation. Emerging evidence from Scandinavia and the UK show that cancer is diagnosed in $11-21 \%$ of patients referred to multidisciplinary diagnostic centres and that serious disease is diagnosed in $22-34 \% .{ }^{52}$

Recommendations for future research

- To investigate the feasibility and usefulness of patients being weighed routinely on every visit to primary care physicians to help detect unexpected weight loss

- To investigate monitoring of biochemical and radiological signatures of cachexia to detect weight loss related to cancer

- To evaluate the diagnostic yield of multidisciplinary diagnostic centres to see how their different diagnostic approaches compare

\section{What should we do in the light of the uncertainty?}

It is unclear how to investigate people presenting to primary care with weight loss but no other symptoms. Box 4 describes some approaches suggested in clinical reviews, but the data are usually obtained from studies of older people hospitalised for investigation. ${ }^{1434-36}$ 
Box 4: Summary of approaches to investigating weight loss from clinical reviews

\section{Vanderschueren $2005^{4}$}

Population-Adults

Weight loss $\rightarrow 5 \%$ in 6-12 months should prompt clinical evaluation. Seek numerical verification of weight loss and confirm it is involuntary

Investigation:

Medical history and associated complaints including

tobacco/alcohol use; medications (such as diuretics, digoxin,

biguanides, leflunomide, SSRIs); psychosocial factors (such as bereaved, institutionalised, mental health); dietary history; travel history; sexual risk behaviour, thorough physical examination

Baseline tests-CBC with differential, renal function, LFTs, albumin, TFTs, blood sugar, markers of inflammation, iron studies, urine analysis, faecal occult blood tests, CXR, USS of abdomen and pelvis

Additional investigations as indicated by clues obtained with the above tests

\section{Rolland $2006^{36}$}

Population-Outpatient older adults

Weight loss $\longrightarrow 5 \%$ in 6 months

Investigation-Assess for biochemical dehydration and complete SNAQ questionnaire

SNAQ negative ( $>14$ points)—Suspected sarcopenia: trial of resistance exercise training. Suspected malabsorption: test vitamin $A$ or $\beta$ carotene

SNAQ positive ( $<14$ points) - Suspected cachexia: test CRP and albumin. Suspected anorexia: use "meals on wheels" mnemonic

\section{McMinn $2011^{35}$}

Population-Older adults

Weight loss - 5\% over 6-12 months, although smaller losses may be important in frail elderly people

Investigation:

Comprehensive history and physical exam using "meals on wheels" mnemonic and "9 Ds" of weight loss in elderly

Baseline tests-FBC, Renal function, LFTs including GGT, albumin, TFTs, CRP, ESR, glucose, LDH, CXR, urine analysis, FOBT.

If results are normal, 3 months of "watchful waiting" is preferable to further blind investigations

\section{Gaddey 2014 ${ }^{34}$}

Population-Older adults

Weight loss $-25 \%$ within $6-12$ months, unintentional. If $n$ baseline weight available, evidence of change in clothing size confirmation of weight loss by a relative or friend, and a numerical estimate of weight loss can be used

History and physical examination, in particular ask about fever fatigue, dysphagia, oral/gum problems, dyspnoea, exertional fatigue, indigestion, abdominal pain, change in stool pattern, early satiety. Check medications and social and psychological history Assess nutritional status, such as with the Nutritional Health Checklist

Baseline tests-CBC, basic metabolic panel, LFTs, TFTs, CRP, ESR, glucose, LDH, CXR, FOBT, and possibly USS of abdomen If baseline tests are normal, close observation for 3-6 months is justified

\section{Wong 2014}

Population-Adults

Weight loss $\longrightarrow 5 \%$ within 6-12 months, unintentional. Use clinical judgement to guide investigation in patients with weight loss $<5 \%$ or longer duration

History and physical exam covering differential diagnoses (see box 1)

Baseline tests-CBC, LFTs, albumin, renal function, glucose, calcium, TSH, HIV, ESR, CRP, LDH, PSA, CXR

Consider abdominal USS or CT and age-appropriate screening for breast, colorectal, and cervical cancer

SSRIs = selective serotonin reuptake inhibitors. $\mathrm{CBC}=$ complete blood count. LFTs = liver function tests. TFTs = thyroid function tests $\mathrm{CXR}=$ chest $\mathrm{x}$ ray. $\mathrm{USS}=$ ultrasound scan. $\mathrm{CRP}=\mathrm{C}$ reactive protein $\mathrm{FBC}=$ full blood count. GGT = gamma-glutamyl transferase. $\mathrm{ESR}=$ erythrocyte sedimentation rate. $\mathrm{LDH}=$ lactate dehydrogenase. FOBT = faecal occult blood test. $\mathrm{PSA}=$ prostate-specific antigen. $\mathrm{CT}=$ computed tomography.

SNAQ questionnaire = Q1. My appetite is: A. V. poor, B. Poor, C. Average, D. Good, E. V. good. Q2. I feel full after eating: A. a few mouthfuls, B. 1/3 of a meal, C. $>1 / 2$ a meal, D. most of the meal, E. hardly ever. Q3. Food tastes: A. V. bad, B. Bad, C. Average, D. Good, E. V. good. Q4. Meals I normally eat each day: A. <1, B. 1, C. 2, D. 3, E. >3. (Score: $A=1, B=2, C=3, D=4, E=5$.)

MEALS ON WHEELS = Medication effects, Emotional problems (especially depression), Anorexia nervosa, alcoholism, Late life paranoia, Swallowing disorders, Oral factors (poorly fitting dentures, caries), No money, Wandering and other dementia related behaviours, Hyper/hypothyroidism, hyperparathyroidism, hypoadrenalism, Enteric problems, Eating problems (such as inability to feed self), Low salt, low cholesterol diet, Stones, social problems (such as isolation, poverty, mobility)

9 Ds of weight loss in elderly = Dementia, Depression, Disease (acute and chronic), Dysphagia, Dysgeusia, Diarrhoea, Drugs, Dentition, Dysfunction (functional disability), Don't know

In the UK, NICE reviewed the evidence in 2015 from studies in primary care and recommends investigating patients with weight loss and localising symptoms for cancer (table 3). ${ }^{37}$ These guidelines focus on ruling out individual cancer types rather than establishing the cause of the symptom. This could lead to multiple referrals for exclusion of specific cancers and a delay in diagnosis. Since then, evidence from the 2018 systematic review indicates that weight loss predicts cancer in patients 60 years and older sufficiently commonly to warrant investigation across cancer sites. ${ }^{5}$ This supports early referral for testing focused on weight loss rather than pathways focused on individual cancer types.

\section{What patients need to know}

- Losing weight without trying to do so is abnormal and should prompt a visit to your doctor

- Most people with unexpected weight loss do not have cancer, but cancer is possible, particularly in adults over 60 years old. Further tests in a hospital might be needed to rule out cancer

- It is unclear how much weight loss, or over what time period, increases the likelihood of cancer

- Report any accompanying symptoms to your doctor as these may help in reaching a diagnosis and guide appropriate investigations

\section{Education into practice}

-Which clinical scenarios prompt you to measure your patient's weight?

- What is your current approach to the investigation of unexpected weight loss? How would you alter this based on reading this article?

\section{How patients were involved in the creation of this article}

Four patient representatives who were advisory panel members for the study related to this article reviewed earlier versions of this article. They provided comments leading to revisions to improve clarity. A patient reviewer kindly reviewed this article for The $B M J$. He suggested emphasising the importance of weight measurement in primary care, but also cautioned about "false positives" (when a patient with weight loss is sent for specialist investigations but turns out not to have cancer) which could cause unnecessary alarm to the patient and family and is wasteful of resources. We have presented guidance for clinicians on identifying patients at higher risk of cancer and when to refer for investigations. We are grateful for the input from patients.

Contributors: BDN conceived and drafted the first version of the manuscript. WH, $\mathrm{PA}$, and FDRH commented on multiple versions of the manuscript. All authors agreed on the final version. BDN is the guarantor.

Funding: BDN is funded as part of the National Institute for Health Research (NIHR) Doctoral Research Fellowship (DRF-2015-08-18). The views expressed are those of the authors and not necessarily those of the NHS, the NIHR, or the Department of Health. WH is co-principal investigator of the multi-institutional CanTest Research Collaborative funded by a Cancer Research UK Population Research Catalyst 
award (C8640/A23385). PA is an NIHR senior investigator and funded by the NIHR Oxford Biomedical Research Centre and CLAHRC. FDRH has part funding from the NIHR School for Primary Care Research, the NIHR Collaboration for Leadership in Health Research and Care (CLARHC) Oxford, the NIHR Oxford Biomedical Research Centre (BRC,)UHT), and the NIHR Oxford Medtech and In-Vitro Diagnostics Co-operative (MIC).

Competing interests: We have read and understood the BMJ Group policy on declaration of interests and have no relevant interests to declare.

Provenance and peer review: Commissioned; externally peer reviewed.

1 Wong CJ. Involuntary weight loss. Med Clin North Am 2014;98:625-43. 10.1016/.jmcna.2014.01.012 24758965

2 Bhaskaran K, Douglas I, Forbes H, dos-Santos-Silva I, Leon DA, Smeeth L. Body-mass index and risk of 22 specific cancers: a population-based cohort study of 5.24 million UK adults. Lancet 2014;384:755-65. 10.1016/S0140-6736(14)60892-8 25129328

3 Wallace Jl, Schwartz RS. Epidemiology of weight loss in humans with special reference to wasting in the elderly. Int $J$ Cardiol 2002;85:15-21.

10.1016/S0167-5273(02)00246-2 12163206

4 Vanderschueren $\mathrm{S}$, Geens $\mathrm{E}$, Knockaert D, Bobbaers $\mathrm{H}$. The diagnostic spectrum of unintentional weight loss. Eur J Intern Med 2005;16:160-4. 10.1016/j.ejim.2005.01.004 15967329

5 Nicholson BD, Hamilton W, O'Sullivan J, Aveyard P, Hobbs FR. Weight loss as a predictor of cancer in primary care: a systematic review and meta-analysis. Br J Gen Pract 2018;68:e311-22. 10.3399/bjgp18X695801 29632004

6 Hamilton W, Lancashire R, Sharp D, Peters TJ, Cheng K, Marshall T. The risk of colorectal cancer with symptoms at different ages and between the sexes: a case-control study. BMC Med 2009:7:17. 10.1186/1741-7015-7-17 19374736

7 Walter FM, Mills K, Mendonça SC, etal . Symptoms and patient factors associated with diagnostic intervals for pancreatic cancer (SYMPTOM pancreatic study): a prospective cohort study. Lancet Gastroenterol Hepatol 2016;1:298-306 10.1016/S2468-1253(16)30079-6 28404200

8 Keane MG, Horsfall L, Rait G, Pereira SP. A case-control study comparing the incidence of early symptoms in pancreatic and biliary tract cancer. BMJ Open 2014;4:e005720. 10.1136/bmjopen-2014-005720 25410605

9 Curless R, French J, Williams GV, James OF. Comparison of gastrointestinal symptoms in colorectal carcinoma patients and community controls with respect to age. Gut 1994;35:1267-70. 10.1136/gut.35.9.1267 7959235

10 Hamilton W, Round A, Sharp D, Peters TJ. Clinical features of colorectal cancer before diagnosis: a population-based case-control study. Br J Cancer 2005;93:399-405. 10.1038/s.bjc.6602714 16106247

11 Hamilton W, Lancashire R, Sharp D, Peters TJ, Cheng K, Marshall T. The risk of colorectal cancer with symptoms at different ages and between the sexes: a case-control study. BMC Med 2009;7:17. 10.1186/1741-7015-7-17 19374736

12 Collins GS, Altman DG. Identifying patients with undetected colorectal cancer: an independent validation of QCancer (Colorectal). Br J Cancer 2012;107:260-5. 10.1038/bjc.2012.266 22699822

13 Hippisley-Cox J, Coupland C. Identifying patients with suspected colorectal cancer in primary care: derivation and validation of an algorithm. Br J Gen Pract 2012;62:e29-37. 10.3399/bjgp12X616346 22520670

14 Hippisley-Cox J, Coupland C. Identifying patients with suspected gastro-oesophageal cancer in primary care: derivation and validation of an algorithm. $\mathrm{Br} J$ Gen Pract 2011;61:e707-14. 10.3399/bjgp11X606609 22054334

15 Collins GS, Altman DG. Identifying patients with undetected gastro-oesophageal cancer in primary care: External validation of QCancer ${ }^{\circledR}$ (Gastro-Oesophageal). Eur J Cancer 2013;49:1040-8. 10.1016/j.ejca.2012.10.023 23159533

16 Stapley S, Peters TJ, Neal RD, Rose PW, Walter FM, Hamilton W. The risk of oesophago-gastric cancer in symptomatic patients in primary care: a large case-control study using electronic records. Br J Cancer 2013;108:25-31. 10.1038/bjc.2012.551 23257895

17 Hamilton W, Peters TJ, Round A, Sharp D. What are the clinical features of lung cancer before the diagnosis is made? A population based case-control study. Thorax 2005;60:1059-65. 10.1136/thx.2005.045880 16227326

18 Iyen-Omofoman B, Tata LJ, Baldwin DR, Smith CJP, Hubbard RB. Using socio-demographic and early clinical features in general practice to identify people with lung cancer earlier. Thorax 2013;68:451-9. 10.1136/thoraxjnl-2012-202348 23321602

19 Shephard EA, Neal RD, Rose P, Walter FM, Litt EJ, Hamilton WT. Quantifying the risk of multiple myeloma from symptoms reported in primary care patients: a large case-control study using electronic records. Br J Gen Pract 2015;65:e106-13. 10.3399/bjgp15X68354525624306

20 Hippisley-Cox J, Coupland C. Symptoms and risk factors to identify women with suspected cancer in primary care: derivation and validation of an algorithm. $\mathrm{Br} J$ Gen Pract 2013;63:e11-21. 10.3399/bjgp13X660733 23336450

21 Hippisley-Cox J, Coupland C. Symptoms and risk factors to identify men with suspected cancer in primary care: derivation and validation of an algorithm. $\mathrm{Br} J$ Gen Pract 2013;63:e1-10. 10.3399/bjgp13X660724 23336443

22 Shephard EA, Neal RD, Rose PW, Walter FM, Hamilton WT. Quantifying the risk of non-Hodgkin lymphoma in symptomatic primary care patients aged $\geq 40$ years: a large case-control study using electronic records. Br J Gen Pract 2015;65:e281-8. 10.3399/bjgp15X684793 25918332

23 Lim AWW, Mesher D, Gentry-Maharaj A, etal. Predictive value of symptoms for ovarian cancer: comparison of symptoms reported by questionnaire, interview, and general practitioner notes. J Nat/ Cancer Inst 2012;104:114-24. 10.1093/inci/djr486 22247022
24 Collins GS, Altman DG. Identifying women with undetected ovarian cancer: independent and external validation of $\mathrm{QCancer}\left({ }_{(}^{(}\right)$(Ovarian) prediction model. Eur J Cancer Care (Engl) 2013;22:423-9. 10.1111/ecc.12015 23121234

25 Hippisley-Cox J, Coupland C. Identifying women with suspected ovarian cancer in primary care: derivation and validation of algorithm. BMJ 2011;344:d8009 10.1136/bmj.d8009 22217630

26 Holly EA, Chaliha I, Bracci PM, Gautam M. Signs and symptoms of pancreatic cancer: a population-based case-control study in the San Francisco Bay area. Clin Gastroenterol Hepatol 2004:2:510-7. 10.1016/S1542-3565(04)00171-5 15181621

27 Hippisley-Cox J, Coupland C. Identifying patients with suspected pancreatic cancer in primary care: derivation and validation of an algorithm. Br J Gen Pract 2012;62:e38-45 10.3399/bjgp12X616355 22520674

28 Collins GS, Altman DG. Identifying patients with undetected pancreatic cancer in primary care: an independent and external validation of QCancer( $(\Theta)$ (Pancreas). Br J Gen Pract 2013;63:e636-42. 10.3399/bjgp13X671623 23998844

29 Stapley S, Peters TJ, Neal RD, Rose PW, Walter FM, Hamilton W. The risk of pancreatic cancer in symptomatic patients in primary care: a large case-control study using electronic records. Br J Cancer 2012;106:1940-4. 10.1038/bjc.2012.190 22617126

30 Hamilton W, Sharp DJ, Peters TJ, Round AP. Clinical features of prostate cancer before diagnosis: a population-based, case-control study. Br J Gen Pract 2006;56:756-62.17007705

31 Hippisley-Cox J, Coupland C. Identifying patients with suspected renal tract cancer in primary care: derivation and validation of an algorithm. Br J Gen Pract 2012;62:e251-60. 10.3399/bjgp12X636074 22520912

32 Collins GS, Altman DG. Identifying patients with undetected renal tract cancer in primary care: an independent and external validation of QCancer ${ }^{\circledR}$ (Renal) prediction model. Cancer Epidemiol 2013;37:115-20. 10.1016/..canep.2012.11.005 23280341

33 Nicholson BD, Aveyard P, Hamilton W, etal . The internal validation of weight and weight change coding using weight measurement data within the UK primary care Electronic Health Record. Clin Epidemiol 2019;11:145-55. 10.2147/CLEP.S189989 30774449

34 Gaddey HL, Holder K. Unintentional weight loss in older adults. Am Fam Physician 2014;89:718-22.24784334

35 McMinn J, Steel C, Bowman A. Investigation and management of unintentional weight loss in older adults. BMJ 2011;342:d1732. 10.1136/bmj.d1732 21447571

36 Rolland Y, Kim MJ, Gammack JK, Wilson MM, Thomas DR, Morley JE. Office management of weight loss in older persons. Am J Med 2006;119:1019-26. 10.1016/j.amjmed.2006.02.039 17145241

37 Hamilton W, Hajioff S, Graham J, Schmidt-Hansen M. Suspected cancer (part 2--adults): reference tables from updated NICE guidance. BMJ 2015;350:h3044. 10.1136/bmj.h3044 26104465

38 Ewing M, Naredi $\mathrm{P}$, Zhang $\mathrm{C}$, Månsson J. Identification of patients with non-metastatic colorectal cancer in primary care: a case-control study. Br J Gen Pract 2016;66:e880-6. 10.3399/bjgp16X687985 27821670

39 Shephard EA, Neal RD, Rose PW, Walter FM, Hamilton W. Symptoms of adult chronic and acute leukaemia before diagnosis: large primary care case-control studies using electronic records. Br J Gen Pract 2016:66:e182-8. 10.3399/bjgp16X683989 26917658

40 Hamilton W, Barrett J, Stapley S, Sharp D, Rose P. Clinical features of metastatic cancer in primary care: a case-control study using medical records. Br J Gen Pract 2015;65:e516-22. 10.3399/bjgp15X686077 26212847

41 Koo MM, Hamilton W, Walter FM, Rubin GP, Lyratzopoulos G. Symptom signatures and diagnostic timeliness in cancer patients: a review of current evidence. Neoplasia 2018:20:165-74. 10.1016/.neo.2017.11.005 29253839

42 Fearon K, Strasser F, Anker SD, etal . Definition and classification of cancer cachexia: an international consensus. Lancet Oncol 2011;12:489-95. 10.1016/S1470-2045(10)70218-7 21296615

43 Olson SH, Xu Y, Herzog K, etal . Weight loss, diabetes, fatigue, and depression preceding pancreatic cancer. Pancreas 2016:45:986-91. 10.1097/MPA.0000000000000590 26692445

44 Hamilton W, Round A, Sharp D, Peters TJ. Clinical features of colorectal cancer before diagnosis: a population-based case-control study. Br J Cancer 2005;93:399-405. 10.1038/sj.bjc.6602714 16106247

45 NIHR PROSPERO. A systematic review of the screening and assessment of cachexia by healthcare setting. 2018. https://www.crd.york.ac.uk/prospero/display_record.php? RecordID $=87087$.

46 Caan BJ, Cespedes Feliciano EM, Prado CM, etal . Association of muscle and adiposity measured by computed tomography with survival in patients with nonmetastatic breast cancer. JAMA Oncol 2018;4:798-804. 10.1001/jamaoncol.2018.0137 29621380

47 Caan BJ, Meyerhardt JA, Kroenke CH, etal . Explaining the obesity paradox: the association between body composition and colorectal cancer survival (C-SCANS Study). Cancer Epidemiol Biomarkers Prev 2017;26:1008-15.

10.1158/1055-9965.EPI-17-0200 28506965

48 Mayers JR, Wu C, Clish CB, etal . Elevation of circulating branched-chain amino acids is an early event in human pancreatic adenocarcinoma development. Nat Med 2014;20:1193-8. 10.1038/nm.3686 25261994

49 Porporato PE. Understanding cachexia as a cancer metabolism syndrome. Oncogenesis 2016:5:e200. 10.1038/oncsis.2016.3 26900952

50 Loumaye A, Thissen JP. Biomarkers of cancer cachexia. Clin Biochem 2017;50:1281-8. 10.1016/j.clinbiochem.2017.07.011 28739222

51 Roxburgh CS, McMillan DC. Cancer and systemic inflammation: treat the tumour and treat the host. Br J Cancer 2014;110:1409-12. 10.1038/bjc.2014.90 24548867

52 Forster AS, Renzi C, Lyratzopoulos G. Diagnosing cancer in patients with 'non-alarm' symptoms: Learning from diagnostic care innovations in Denmark. Cancer Epidemiol 2018;54:101-3. 10.1016/..canep.2018.03.011 29702426

Published by the BMJ Publishing Group Limited. For permission to use (where not already granted under a licence) please go to http://group.bmj.com/group/rights-licensing/ permissions 


\section{Tables}

\begin{tabular}{|c|c|c|c|c|c|c|c|}
\hline Study and design & $\begin{array}{l}\text { How weight loss } \\
\text { defined }\end{array}$ & Data source & Sample size & Age (years) & Male (\%) & $\begin{array}{l}\text { Positive likelihood } \\
\text { ratio }(95 \% \mathrm{Cl})^{\star}\end{array}$ & $\begin{array}{l}\text { QUADAS } \\
\text { quality score }\end{array}$ \\
\hline \multicolumn{8}{|l|}{ Biliary tree cancer } \\
\hline Keane $2014^{8}$; Ret C-C & Code & UK EHR & 18021 & $\begin{array}{c}\text { Mean } 72(\mathrm{SD} \\
12)\end{array}$ & 47.1 & $3.2(2.4$ to 4.2$)$ & $6 / 7$ \\
\hline \multicolumn{8}{|l|}{ Colorectal cancer } \\
\hline Curless $1994^{9}$; Ret C-C & Pt report & UK questionnaire & 546 & $25-93$ & 56 & $5.9(5$ to 6.9$)$ & $4 / 7$ \\
\hline Hamilton $2005^{10}$; Ret C-C & Any entry & UK paper and EHR & 2093 & $>40$ & 50.7 & $5.1(4.2$ to 6.3$)$ & $6 / 7$ \\
\hline Hamilton 2009"1 ; Ret C-C & Measured & UK EHR & 43791 & $>30$ & NR & $2.6(2.4$ to 2.8$)$ & $6 / 7$ \\
\hline Collins 2012 $2^{12}$; Ret Chrt & Code & UK EHR & 2135540 & $30-84$ & 49.6 & $4.4(3.8$ to 5$)$ & $7 / 7$ \\
\hline Hippisley-Cox 2012 $2^{13}$; Ret Chrt & Code & UK EHR & 1235547 & $30-84$ & 50.2 & 3.6 (3 to 4.4$)$ & $6 / 7$ \\
\hline \multicolumn{8}{|l|}{ Gastro-oesophageal cancer } \\
\hline Hippisley-Cox 2011 $1^{14}$; Ret Chrt & Code & UK EHR & 963040 & $30-84$ & 50.2 & 8.5 (7 to 10.2$)$ & $6 / 7$ \\
\hline Collins $2013^{15}$; Ret Chrt & Code & UK EHR & 2140194 & $30-84$ & 49.6 & $9.4(8.2$ to 10.7$)$ & $7 / 7$ \\
\hline Stapley $2013^{16}$; Ret C-C & Code & UK EHR & 40348 & $\geq 40$ & 64.2 & 9.8 (9.1 to 10.6$)$ & $6 / 7$ \\
\hline \multicolumn{8}{|l|}{ Lung cancer } \\
\hline Hamilton $2005^{17}$; Ret C-C & Any entry & UK paper and EHR & 1482 & $>40$ & 68.8 & $6.2(4.9$ to 7.9$)$ & $6 / 7$ \\
\hline $\begin{array}{l}\text { Iyen-Omofoman } 2013^{18} ; \text { Ret } \\
\text { C-C }\end{array}$ & Code & UK EHR & 132805 & $>40$ & 49.1 & $4.5(4.1$ to 5.1$)$ & $6 / 7$ \\
\hline \multicolumn{8}{|l|}{ Myeloma } \\
\hline Shephard $2015^{19}$; Ret C-C & Code & UK EHR & 14860 & $\geq 40$ & 52.5 & $5.6(4.6$ to 6.8$)$ & $6 / 7$ \\
\hline \multicolumn{8}{|l|}{ Multiple cancers } \\
\hline Hippisley-Cox 2013 $3^{20}$; Ret Chrt & Code & UK EHR & 667603 & $25-89$ & 0 & $3.5(3.2$ to 3.8$)$ & $7 / 7$ \\
\hline 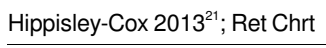 & Code & UK EHR & 679174 & $25-89$ & 100 & $6.8(6.3$ to 7.4$)$ & $7 / 7$ \\
\hline \multicolumn{8}{|l|}{ Non-Hodgkin's lymphoma } \\
\hline Shephard $2015^{22}$; Ret C-C & Code & UK EHR & 23830 & $\geq 40$ & 51.3 & $6.4(5.5$ to 7.4$)$ & $6 / 7$ \\
\hline \multicolumn{8}{|l|}{ Ovarian cancer } \\
\hline Lim $2012^{23}$; Ret C-C & Code & UK GP records & 398 & $50-78$ & 0 & $3.3(1.4$ to 7.9$)$ & $3 / 7$ \\
\hline Collins $2013^{24}$; Ret Chrt & Code & UK EHR & 1054818 & $30-84$ & 0 & 3.3 (2.4 to 4.7$)$ & $7 / 7$ \\
\hline Hippisley-Cox 2012 $2^{25}$; Ret Chrt & Code & UK EHR & 472114 & $30-84$ & 0 & $3.7(2.5$ to 5.7$)$ & $6 / 7$ \\
\hline \multicolumn{8}{|l|}{ Pancreatic cancer } \\
\hline Holly $2004^{26}$; Ret C-C & Pt report. & US questionnaire & 300 & $21-85$ & 54 & $8.4(6.2$ to 11.3$)$ & $3 / 7$ \\
\hline Hippisley-Cox $2012^{27}$; Ret C-C & Code & UK EHR & 971706 & $30-84$ & 50.2 & 8.1 (6.3 to 10.4$)$ & $6 / 7$ \\
\hline Collins $2013^{28}$; Ret Chrt & Code & UK EHR & 2135962 & $30-84$ & 49.6 & 9.7 (7.8 to 12.1$)$ & $7 / 7$ \\
\hline Keane 2014; ; Ret C-C & Code & UK EHR & 19982 & $\begin{array}{c}\text { Mean } 71 \text { (SD } \\
11)\end{array}$ & 47.1 & 6 (5.4 to 6.7$)$ & $6 / 7$ \\
\hline Stapley $2012^{29}$; Ret C-C & Code & UK EHR & 20094 & $\geq 40$ & 48.0 & 15.2 (13.7 to 16.9$)$ & $6 / 7$ \\
\hline \multicolumn{8}{|l|}{ Prostate cancer } \\
\hline Hamilton $2005^{30}$; Ret C-C & Any entry & UK paper and EHR & 1297 & $>40$ & 100 & $11.4(8.6$ to 15.1$)$ & $6 / 7$ \\
\hline \multicolumn{8}{|l|}{ Renal tract cancer } \\
\hline Hippisley-Cox 2012 $2^{31}$; Ret Chrt & Code & UK EHR & 967681 & $30-84$ & 50 & 2.4 (1.8 to 3.4$)$ & $6 / 7$ \\
\hline Collins $2013^{32}$; Ret Chrt & Code & UK EHR & 1081778 & $30-84$ & 49.6 & 2.4 (1.5 to 3.6$)$ & $7 / 7$ \\
\hline
\end{tabular}

* Positive likelihood ratio is how many times more likely is a patient with weight loss to be diagnosed with cancer compared with somebody without weight loss. Ret = retrospective, $\mathrm{C}-\mathrm{C}=$ case-control, $\mathrm{Chrt}=$ cohort, $\mathrm{EHR}=$ electronic health records. 
Table 2| Clinical features associated with $\geq 3 \%$ risk of cancer when patients also complain of weight loss

\begin{tabular}{|c|c|c|c|}
\hline \multirow[b]{2}{*}{ Clinical feature } & \multirow[b]{2}{*}{ Patients' age (years) } & \multicolumn{2}{|c|}{ Positive predictive value (\%) } \\
\hline & & Of clinical feature alone & Of feature + weight loss \\
\hline \multicolumn{4}{|l|}{ Pancreatic cancer } \\
\hline Jaundice & $>60$ & 22.0 & 31.6 \\
\hline \multicolumn{4}{|l|}{ Prostate cancer } \\
\hline Nocturia & $>40$ & 2.2 & 12 \\
\hline Benign rectal exam & $>40$ & 2.4 & 9.4 \\
\hline \multicolumn{4}{|l|}{ Non-Hodgkin's lymphoma } \\
\hline Lymphadenopathy & $>60$ & 13 & $>10$ \\
\hline Raised gamma globulin & $>60$ & 0.2 & 3.5 \\
\hline \multicolumn{4}{|l|}{ Lung cancer } \\
\hline Haemoptysis & $>40$ & 4.8 & 9.2 \\
\hline Thrombocytosis & $>40$ & 1.6 & 6.1 \\
\hline \multicolumn{4}{|l|}{ Gastro-oesophageal cancer } \\
\hline Dysphagia & $>55$ & 4.8 & 9.2 \\
\hline Epigastric pain & $>55$ & 0.9 & 4.2 \\
\hline Gastro-oesophageal reflux & $>55$ & 0.6 & 3.1 \\
\hline \multicolumn{4}{|l|}{ Colorectal cancer } \\
\hline Abnormal rectal exam & $>40$ & 1.5 & 7.4 \\
\hline Abdominal tenderness & $>40$ & 1.1 & 6.4 \\
\hline Haemoglobin $<10$ & $>40$ & 2.3 & 4.7 \\
\hline Rectal bleeding & $>40$ & 2.4 & 4.7 \\
\hline Abdominal pain & $>40$ & 1.1 & 3.4 \\
\hline Diarrhoea & $>40$ & 0.9 & 3.1 \\
\hline Constipation & $>40$ & 0.4 & 3.0 \\
\hline
\end{tabular}




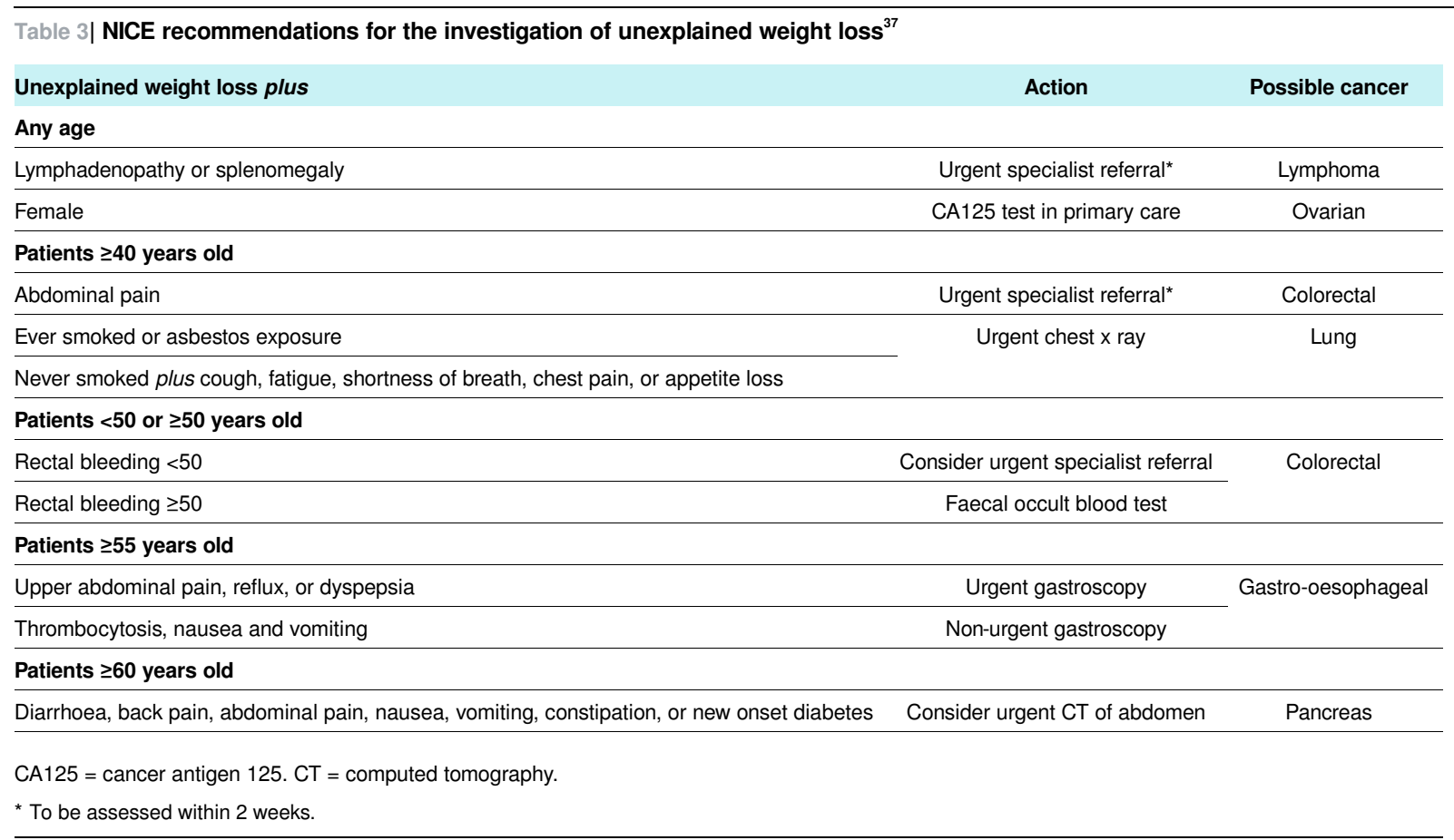

